\title{
LEARNING THROUGH SERIOUS GAMES: A DIGITAL DESIGN MUSEUM FOR EDUCATION
}

\author{
C. Bolognesi ${ }^{1 *}$, D. Aiello ${ }^{2}$ \\ ${ }^{1}$ Politecnico di Milano, ABC Department, 20135 Milano, Italy - cecilia.bolognesi@ polimi.it \\ ${ }^{2}$ University of Catania, Department of Civil Engineering and Architecture, Italy - damianoaiello@ gmail.com
}

Commission V

KEY WORDS: Serious Game, Virtual Reality, Digital Survey, 3D Modeling, Achille Castiglioni, Virtual Museum

\begin{abstract}
:
This project aims to demonstrate the communicative and educational possibilities offered by ICT in the promotion and enhancement of museum heritage. To this end, the researchers have outlined a workflow that includes both a technical-engineering component and a psychological component for the development of a serious game, designed to educate users in a pleasant way and applied to a small museum institution located in an ancient building in the city of Milan: the Studio Museo Achille Castiglioni, which hosts a collection of design objects created by one of the most important designers of the 20th century. Virtual Reality was considered the most effective means to make it possible to remotely enjoy the 3D space, thanks to its ability to fully immerse the user in the game space and to physically and emotionally involve him or her through interactive elements, allowing to learn by acting, to live a firstperson experience as the protagonist of the visit and not just as a spectator.
\end{abstract}

\section{INTRODUCTION}

In recent years, museum institutions have gone through a period of great changes and innovations due to the increasingly widespread diffusion of ICT (Information and Communication Technologies), which have provided tools capable of revolutionizing the panorama of museum offerings and the way exhibitions are enjoyed (Anderson, 1999; Hempell et al., 2004; Solano, 2012).

In this context, the traditional idea of a museum as a "mausoleum" (Witcomb, 2003), i.e. as a simple container of ancient artefacts and works of art (destined to be observed preferably by an elite connoisseur), within which the only vehicle of information is represented by panels with text boxes placed next to the exhibits, is gradually being abandoned. This paradigm, in fact, is no longer suitable for contemporary society, because it relegates the visitor to the role of passive spectator and prevents them from concentrating their attention on contemplating the artefacts kept in the museum.

The technological revolution has allowed museum institutions to overcome this original limit, to widen their boundaries, to address a diversified audience in an increasingly conscious way, using equally diversified tools that allow the visitor to be more and more protagonist of the visit. At the same time, the pedagogical role of museums, within which an increasingly vast public is not limited to observing, but is called upon to question itself, to reflect on what it observes and to interact with the works through new technological devices, has been emphasized (Novak et al., 2001).

The ability of contemporary museums to reach new target audiences is perhaps one of the most evident consequences of the introduction of ICT, which now represent an effective tool for integrating the visitor experience (Camarero and Garrido, 2011). At the same time, new technologies bring the museum institution closer to the user, allowing the customization of the visit based on individual needs and promoting a direct involvement of the visitor through the use of interactive installations. In this way not only the users, who can meet their needs through the museum experience, but also the museum institutions themselves, who can implement their own service by fostering a better valorisation of their heritage (Srinivasan et al., 2009), obtain benefits.

In this climate of renewal, ICOM (International Council of Museums) elaborated a new definition of museum, according to which a museum is "a permanent, non-profit institution, at the service of society and its development, open to the public, which acquires, conserves, researches, communicates and exhibits, for study, education and entertainment, material evidence of people and their environment" (ICOM, 2007).

The application of ICT in museums has also led to the birth of the concept of "edutainment", a neologism born from the combination of the words "education" and "entertainment". This term represents one of the key functions of today's museum institutions, which are increasingly striving to develop new ways to promote education, knowledge and learning for users without ever separating these components from the feeling of fun and pleasure (Jegers and Wiberg, 2005).

The concept of edutainment is at the heart of the serious game, a type of game designed to educate while having fun. This tool can become particularly effective when applied to the museum environment, both because, by promoting innovative forms of enjoyment, it helps to attract categories of users often far from museums, and because it lends itself, thanks to its ductile nature, to deal with different themes, such as cultural awareness (Froschauer et al, 2010; Huang et al., 2013), historical reconstruction (Christopoulos et al., 2011; Doulamis et al., 2011) and heritage awareness (Cao et al., 2011; Bellotti et al., 2012; Froschauer et al. 2011, 2013; Tangui 2013).

In some of the most complex cases, serious games are enriched with the potential offered by Virtual Reality (VR): in this regard, the museum sector is perhaps one of the contexts in which VR reaches its maximum communication potential

\footnotetext{
* Corresponding author
} 
(Aiello et al., 2019; Guazzaroni, 2019; Kang et al., 2019; Kargas et al., 2019), firstly because it allows to come into contact with the museum artworks in a way that was unthinkable until recently, and secondly because, when used as a support to enhance a real museum, it is able to indefinitely expand the boundaries of the physical place and give greater visibility to small institutions on the margins of large museum circuits. The absence of spatial barriers within the virtual dimension also makes it possible to create, through VR, digital databases that make a potentially considerable number of artefacts accessible and interrogable, favouring contact with works that are often not exhibited to the public in the real world (because they are in restoration or stored).

The research described herein focuses precisely on the development of an immersive and interactive serious game, which allows visitors to visit, in an innovative way, an important museum institution in the city of Milan, the Studio Museo Achille Castiglioni, containing iconic works by one of the most important designers of the 20th century. On the basis of the analysis on the theoretical concept of serious games, the researchers have proposed a methodological procedure for the development of the virtual simulation, which led to the creation of the serious game.

\section{SERIOUS GAME}

This paragraph analyses the concept of serious game and the process behind its development. In general, a serious game is a game with a purpose other than entertainment alone (Abt, 1970; Laamarti et al., 2014): it proposes forms of entertainment that are never an end in themselves but are the prerequisite for a valid learning experience in any field of knowledge.

Serious games are distinguished from leisure games by the addition of pedagogy to the three main elements of computer games: history, art and software. However, the pedagogical/educational content must be subordinate to game and history (Zyda, 2005).

It can be said that every serious game is born from the integration of two components (Gunter et al. 2006):

Motivational factors (Malone, 1980, 1981) of challenge, fantasy and curiosity, which entice the user to play the game. The challenge seems to refer to the intrinsic motivation when it meets certain standards, for example a balance between the player's skills and the difficulty of the game. Imagination refers to the representative part of the game, regardless of whether the representation is realistic or unrealistic. Curiosity refers to the discovery of feedback and auditory and visual aspects. Various studies have used motivational theories to explain how players are emotionally involved in a game.

Educational component, which always provides experiential learning: when you play a serious game, in fact, you learn by doing, i.e. you acquire knowledge through direct, not theoretical, experience.

Various studies have tried to propose models aimed at the analysis and evaluation of existing serious games, as well as the development of new serious games (Barajas, 2014; Rodriguez et al., 2014). All these models try to analyse the right balance and the level of integration between motivational factors and educational component. This is the case, for example, of the RETAIN model (Gunter et al., 2008), designed to support the development of games and to evaluate their strengths and weaknesses. The RETAIN model is based on a scheme consisting of 6 factors that the developer must take into account after defining the learning goals: relevance of the educational content (which consists in presenting the game content in a way that is stimulating for learners, their needs and their learning style, and in ensuring that the levels of education of the game connect with each other); embedding (which concerns the integration between learning, imagination and game. This integration should take place in such a way that, during the game, none of the three elements prevail over the other); transfer (concerns the way new knowledge acquired during the game is transferred into other scenarios or situations, e.g. into new levels of the game); adaptation (change of player behaviour as a result of transfer); immersion (feeling of presence and emotional participation of the player within the game); naturalization of learning objectives (development of a habitual and spontaneous use of the information obtained within the game).

Another development model for serious games is the so-called LM-GM (Learning Mechanic / Game Mechanic) (Arnab, 2014). It is an approach that addresses the problem of designing a game based on the type of learning objectives you want to achieve. Once the "Learning Mechanic" (LM) has been established, the LM-GM model allows to combine it with the game activity ("game mechanic", GM) most suitable to help the player to achieve this educational result.

The LM-GM model focuses exclusively on the game design, without considering elements such as the motivations and objectives of the user. To fill this gap, some researchers (Carvalho et al. 2015) have proposed an implementation of the LM-GM model, which distinguishes between external actions and motivations and internal actions and motivations in the game. In this way, when designing a serious game, external factors such as the context in which the game will be used, the user's culture, the community in which the user lives, the rules of this community, etc. can be taken into account. This model proposes a complete and updated integrated methodology for the design of serious games, able to link the design choices to the expected effects.

In fact, it should be noted that it is difficult to establish a priori the general characteristics that a serious game should have to be defined as such (Haring et al., 2011). The "seriousness" of a game (i.e. its pedagogical function and its educational content) must be assessed on a case-by-case basis, taking into consideration the users' experience, since there may exist games that are intentionally conceived as serious games, but that actually reveal an inconsistent educational component, as well as (on the contrary) there may be games that, although not developed with a deliberate educational purpose, enrich the player's knowledge and therefore can be considered serious games to all intents and purposes. Therefore, the intention of developing a serious game is not enough. The occurrence or not of these intentional effects can only be determined retrospectively by empirical research (Durkin, 2006; Lee and Peng, 2006; Lieberman, 2006; Ritterfeld and Weber, 2006). However, these studies cannot be generalized (Watt, 2009), primarily because of the obvious differences in game design and content, which make each game different from the others.

\section{CASE STUDY}

The Studio Museo Achille Castiglioni is the former studio of Achille Castiglioni, who, with his eclectic and unconventional personality, his aesthetic sensibility and creative genius, was a pioneer of the Italian design and one of its most influential protagonists (Fig. 1). 


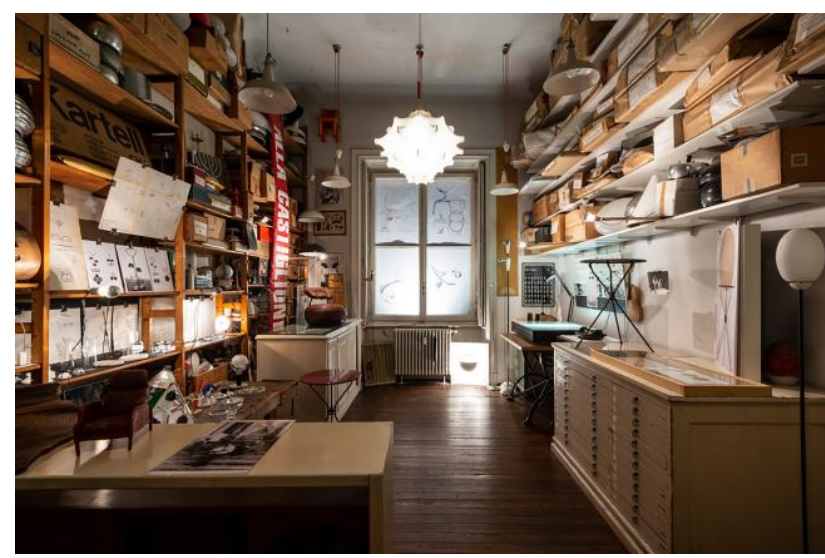

Figure 1. Prototypes Room, Studio Museo Achille Castiglioni. (C) 2018, Fondazione Achille Castiglioni. Used with permission).

Until 1968 he worked with his brother Pier Giacomo, with whom he designed some of the best-known icons in the history of industrial design including Sella and Mezzadro stools as well as Arco and Taccia lamps (now part of the MoMA's permanent collection).

After the Pier Giacomo's death, he continued to create numerous design objects that combine aesthetics and functionality and have become part of the social imaginary of Italian design. (such as Parentesi lamp, Spirale ashtray, Cumano table, Record wristwatch, and Joy bookshelf).

During his career he has won several awards such as eight Compasso d'Oro (1955-1979) - the first and most recognized design prize in the world -, one Triennale Bronze Medal (1947), two Silver Medals (1957, 1963), two Gold Medals (1957, 1960), and two Triennale Grand Prix (1951, 1954).

His works have been widely exhibited in the most important museums in the world including the MoMA in New York, the Victoria \& Albert Museum of London, the Kunstgewerbemuseum Zürich, and the Vitra Museum in Weilam-Rhein.

Four years after Achille Castiglioni's death in 2002, his studio was opened to the public thanks to an agreement between his heirs and the Triennale di Milano. In order to guarantee the enjoyment and promotion of the site and the works it houses, and to develop the many projects in which the Studio Museo is involved, the Achille Castiglioni Foundation, whose main objective is to catalogue (also through innovative methods) the considerable heritage left by the architect (projects, drawings, photos, models, conferences, objects, books, magazines), was established on December 14, 2011. Another important task of the Foundation is to raise awareness of the designer's creative genius and of his works outside the physical boundaries of the museum. For this reason, the Foundation has warmly welcomed the proposal for the digitization and virtual fruition of the museum and the extraordinary heritage it hosts.

The Studio Museo, which represents a small museum in the Milanese cultural panorama, is articulated in four rooms: the Prototype room, which hosts the prototypes and the study models of the objects designed by Castiglioni; the Drafting machines room, which currently hosts temporary exhibitions; the Mirror room, where it is possible to observe anonymous objects that Achille Castiglioni collected during his life; the Meeting room, where some of the objects that have made the history of design are stored (Fondazione Achille Castiglioni, 2014).
Admiring the works of art in the place where they were conceived, the visitor has the possibility to closely understand the methodological approach behind the creative process of each design work.

\section{ADOPTED METHODOLOGY}

In this experimentation a procedure for the development of a serious game was proposed, which refers to previous research. This methodology is based on the assumption that, in order to create a serious game, it is necessary to take into account the learning needs of the user, his social and cultural context and learning methodology, as well as various technical aspects related to the level of accuracy, interactivity, immersion, fun, etc. The ultimate goal of the experimentation was to test the effectiveness and potential of the serious game as a means to give visibility to the works exhibited in the Studio Museo (as well as to the artefacts that are not visible in the real museum, because they are kept in other places), creating a virtual catalogue and developing an experience with an educational function for users. The methodological path developed is articulated in the following steps:

- $\quad$ Concept design, during which the objectives of the game, the target audience, the pedagogical mechanisms (through which knowledge will be transferred to the learners) and the storytelling are established;

- Digital assets creation, in which digital resources are created, i.e. everything needed to develop the game, e.g. 3D objects, music, sounds, maps, 2D images, etc.

Game development, during which the serious game is created and integrated with menus, options, etc. within the game engine.

Testing stage, during which the game is tested and evaluated from various points of view (technical, absorption of knowledge, usability, utility) to understand its strengths and weaknesses.

Implementation, during which all the information collected during the previous stage is analysed in order to make corrections and improvements.

Any corrections and improvements identified during the implementation stage can lead to redefine the workflow phases following a cyclical scheme and allowing to constantly monitor and review the serious game (Fig. 2).
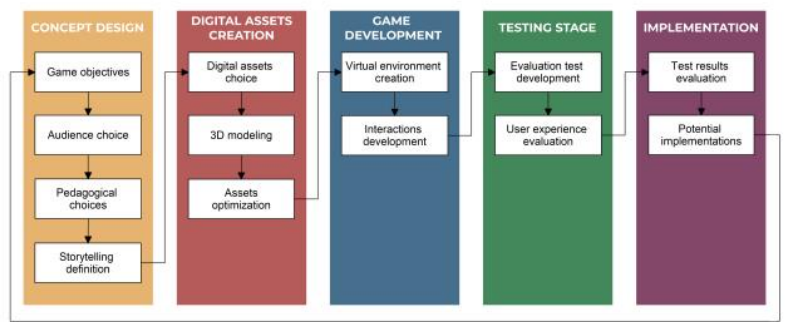

Figure 2. Adopted methodological workflow for the development of serious games.

\subsection{Concept design}

This phase was necessary to establish which tools to use to give life to the serious game, which users to address and how to 
organize the educational components, capture the interest of users and elaborate the storytelling of the museum experience. To this end, it was first decided to develop the serious game in the framework of a virtual reality simulation, able to allow the user to visit the Studio Museo. The VR, in fact, is the most effective tool to break down the spatial boundaries and limits of creativity, as well as to create immersive and interactive experiences able to emotionally involve the user in a totalizing way.

Secondly, an attempt was made to establish the target to which the simulation would be addressed. Considering that in this case we are dealing with a niche museum exhibition, the first recipients of the experience are certainly experts in the field, including architects, engineers, design enthusiasts. However, we tried not to limit ourselves to an excessive sectionalisation, taking into account also potential categories of wider and heterogeneous users in terms of interests, age, belonging groups (such as tourists, families, students). For this reason, it was decided to make the experience as simple and immediate as possible and to include information content that is not too specialised and within everyone's reach, so as not to exclude any category.

Subsequently, it was decided how to bring the user into contact with the creative genius of Castiglioni, giving the virtual experience its pedagogical content, emphasized by the possibility, offered by VR, to interact with the environment and modify it. In order to make the simulation instructive, it was decided to use playful devices that would stimulate the curiosity of visitors, considering that the game is the most effective way to increase cognitive faculties and encourage the learning of new content. In this regard, reference was made to the concept of "learning by acting", which provides that learning is more effective if accompanied by a first-person experience.

The next step was the definition of a storytelling of the virtual experience, developed thanks to the contribution of Castiglioni's heirs. The basic idea was to allow the user maximum freedom of movement in the 3D space and to guarantee a sense of presence within the simulation, through total immersion in the virtual space and the possibility to interact with the surrounding environment. By exploring the virtual museum, the user can thus come into contact with design objects displayed in the context in which they were conceived. To this end, it was decided to enrich the virtual museum collection also with artefacts, designed by Castiglioni, which are not currently kept in the real museum but are nevertheless linked to this place, because of their great value and the memories they contain. All the objects will be associated with easily accessible information (in the form of text, audio, video, etc.) that can be consulted during the visit, providing notions about the history and the creative process of the designer. In this way, the user takes part in a visit to discover the life of Castiglioni, understanding his creative genius, originality, unique personality and interests.

\subsection{Digital assets creation}

During this phase, it was chosen the digital assets that would be part of the virtual experience and how they would be developed. In this regard, in order to obtain the information necessary for the digital reconstruction of the museum's architectural envelope, it was decided to digital survey all the exhibition rooms using the laser scanning technique. The survey was carried out through a Leica BLK 360 laser scanner, an instrument $165 \mathrm{~mm}$ in height $\mathrm{x} 100 \mathrm{~mm}$ in diameter, with a field of view of $360^{\circ}$ wide horizontally and $300^{\circ}$ vertically, a scanning range of 0.6 - 60 meters, a scanning accuracy of $4 \mathrm{~mm}$ at $10 \mathrm{~m}$ and $7 \mathrm{~mm}$ at $20 \mathrm{~m}$ and a remarkable acquisition speed (up to $360,000 \mathrm{pts} / \mathrm{sec}$ ). BLK 360 was used to acquire 21 scans in "high resolution" mode with the camera off (considering that the chromatic data was not necessary for modelling the architectural elements) in order to reduce the acquisition time. The 21 point clouds obtained from these scans were automatically aligned during processing through the Cloud to Cloud method. The complete point cloud of the entire museum is made up approximately by 170 million points (Fig. 3).
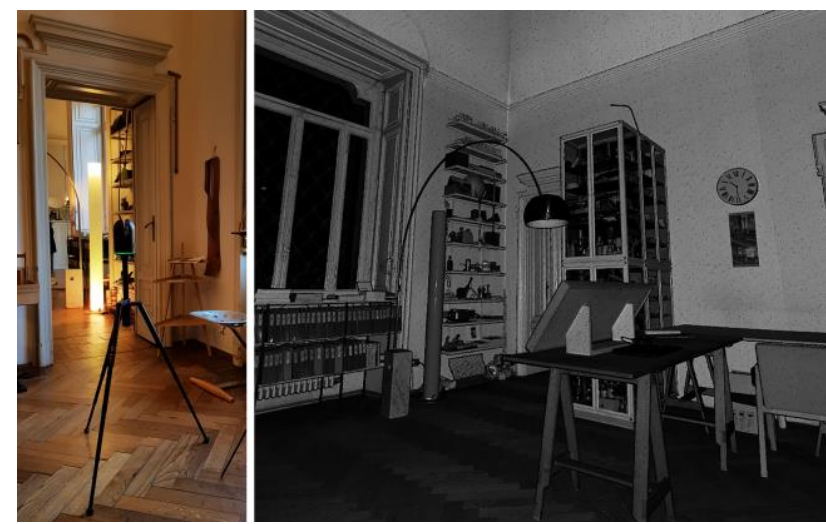

Figure 3. On the left, Leica BLK 360 laser scanner during surveying phases; on the right, view of the laser scanner point cloud.

The numerical model was then imported into CloudCompare (a point cloud management software) and converted into a mesh, a three-dimensional object consisting of a network of polygonal faces.

The mesh was used as a basis to model the museum environments through Rhinoceros, a 3D modelling software. The 3D reconstruction of this architectural envelope was carried out through reverse modelling, which consists in obtaining from the mesh the generatrix and directrix of the architectural elements. Using these curves, all the rooms of the Studio Museo were reconstructed in the form of NURBS surfaces (acronym which stands for "Non-Uniform Rational Basis-Splines"), lighter and easier to manage than the mesh.

As far as the design objects to be included in the virtual exhibition are concerned, they were first selected with the help of the Foundation, which also provided the graphic works and documentation necessary to carry out an analysis on the geometry of the artefacts. Following this study phase, 50 design objects were modelled on Rhinoceros in the form of NURBS surfaces, extrapolating the generatrix and directrix from the $2 \mathrm{D}$ drawings (Fig. 4).

All the digital assets modeled on Rhino were finally exported as polygonal mesh and imported into the game engine used to develop the virtual simulation.
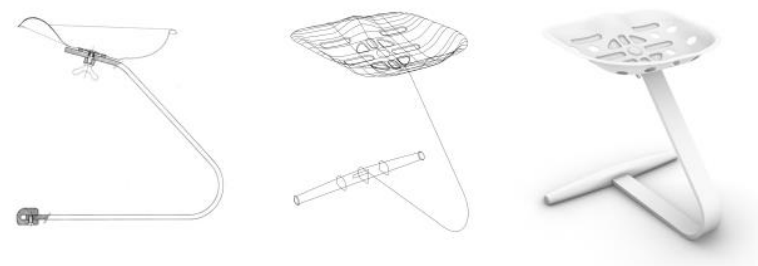

Figure 4. Workflow for modeling the design objects (Rhinoceros). 


\subsection{Game development}

During this phase, the virtual simulation of the Studio Museo was developed inside the game engine Unreal Engine, a source available software chosen for its relatively intuitive use. Unreal Engine is based on the visual scripting system Blueprint, which allows to perform operations through a node interface. Blueprint is extremely flexible and effective because it allows to perform complex actions avoiding the direct use of the $\mathrm{C}++$ programming language.

The hardware chosen to experience the virtual simulation is Oculus Rift S, which represents the most updated version of Oculus Rift. Compared to the previous version, the device is without external sensors, replaced by five cameras positioned along the front of the headset, which interpret the distances and volumes of the environment in which the user is located. The vision of the virtual space is guaranteed by a single fast switch LCD screen with a resolution of $1280 \times 1440$ pixels per eye, which allows to observe particularly sharp and immersive images. Finally, the audio system of the device is characterized by small speakers, placed on the uprights around the user's head, which regulate the sound flow by tracing the movements of the head, and thus immerse him or her in a realistic virtual hearing environment, without isolating from reality (Fig. 5).

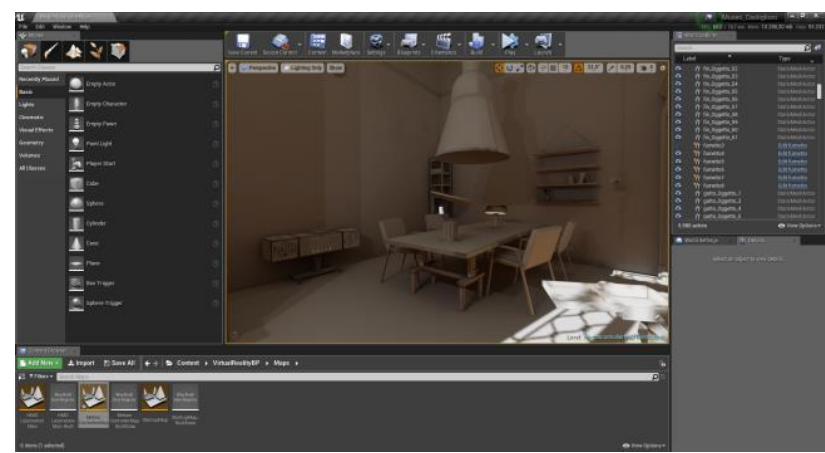

Figure 5. Virtual simulation development in Unreal Engine.

The virtual simulation is conceived to allow the user to move freely within all the environments of the virtual museum, in a similar way to reality. For this purpose, the researchers set up a teleporting system which allows the user to reach the desired area by pointing it with the controllers.

The user can visit in this way every room of the Studio Museo, starting from the Meeting Room, with the Bramante table in the middle, surrounded by four seats (Babela, Lierna, Sedile Mezzadro, Sella). In the room there are other famous objects designed by Castiglioni, such as the two bookshelves Pensile and Lungangolo, the Lapis vase, the Trio and Comodo, the iconic Brionvega RR126 radio, and the lighting fixtures Saliscendi lamp, Taccia table lamp, Snoopy, Lampadina, Parentesi, Toio and Luminator floor lamp. In this case, Castiglioni's life is evoked through his drawings, placed on the drafting machine, and a page from the comic strip Diabolik (on the Bramante table), in which, in homage to the genius of Castiglioni, the Giussani sisters (authors of the comic strip) draw the Taccia lamp (Fig. 6).

The next room is called Mirror Room because of the presence of a large mirror, which represents the most characteristic element of the environment. In front of the mirror there is the Sanluca armchair, flanked by the Servomuto table and the Arco lamp, which is certainly one of the most famous objects designed by Castiglioni. In this room there are also the
Leonardo table with the two Tric chairs, the Servomanto coat hanger, the Stylos floor lamp, and the Mate coffee table (Fig. 7).

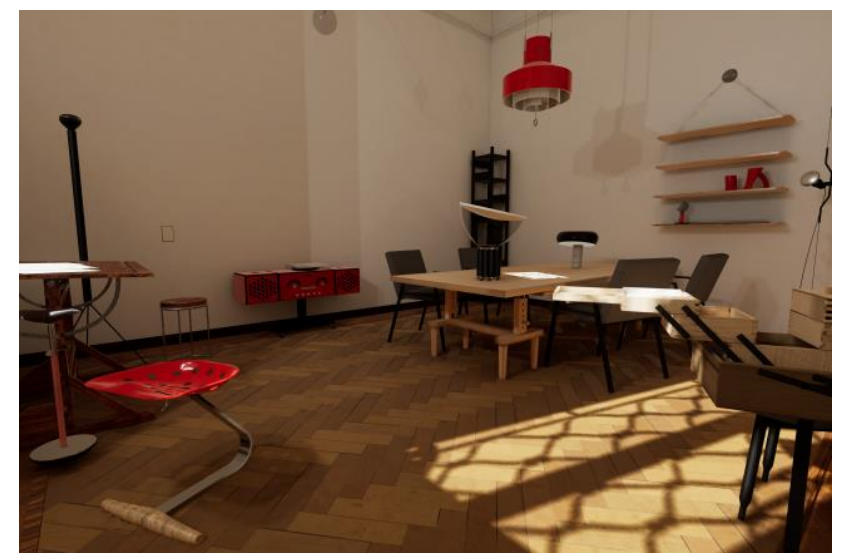

Figure 6. Virtual simulation: view of the Meeting Room.

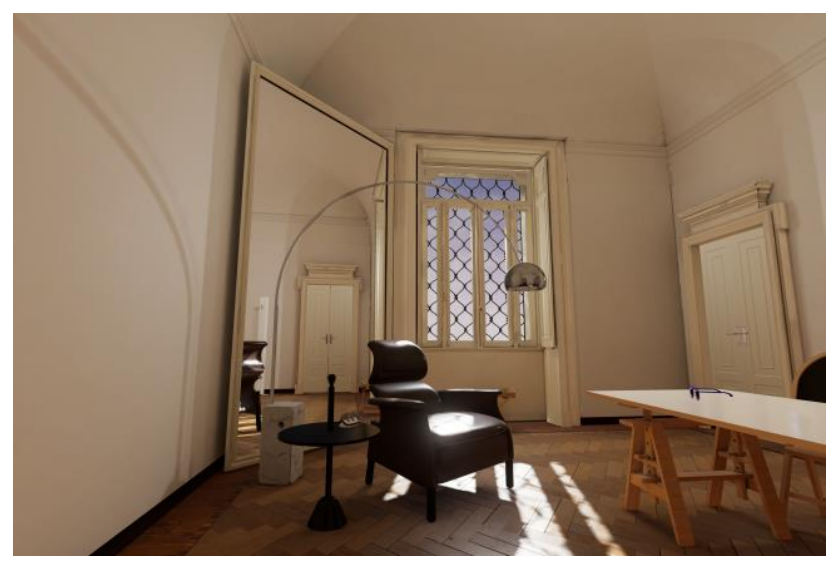

Figure 7. Virtual simulation: view of the Mirror Room.

After passing an environment that hosts posters referring to international exhibitions of Castiglioni's works, the visitor reaches the Drafting Machines Room, where the living room of Villa Olmo (designed by Achille and Pier Giacomo) was recreated with its movable television (Fig. 8).

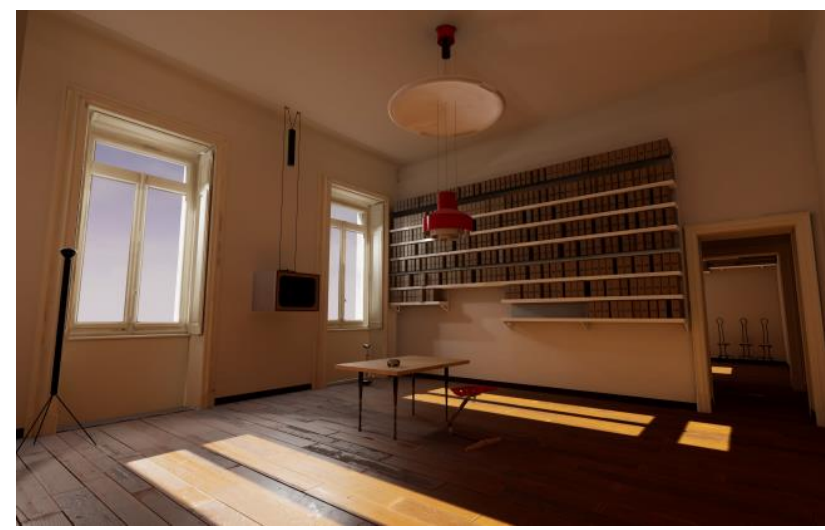

Figure 8. Virtual simulation: view of the Drafting Machines Room set up as the living room of Villa Olmo.

The virtual visit ends inside the Prototype Room, where Castiglioni made his ideas come true. Here you can find, for example, various lamps (Taraxacum '88, Kd6, Relemme, Splugen Brau, Taraxacum '60, Viscontea, Brera, Bibip, Giovi, 
Gatto), two types of chairs (Allunaggio and Spluga), two tables (Cumano and Basello) (Fig. 9).

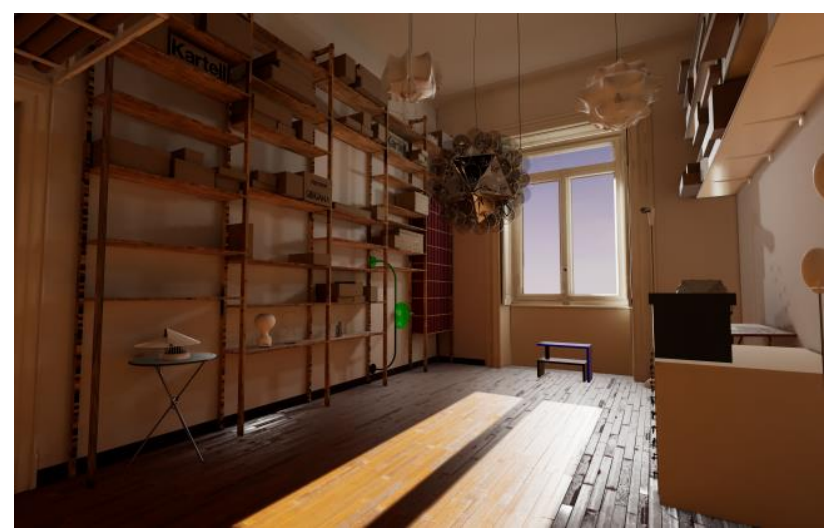

Figure 9. Virtual simulation: view of the Prototypes Room.

To stimulate the visitor's interest and increase the sense of presence within the virtual museum, various interactive elements were created. The first type of interaction concerns the possibility to manipulate objects, which can be moved and analysed closely (such as Castiglioni's drawings, Diabolik's page and some of the design objects), and to interact with light sources.

A more emotionally intense type of interaction concerns the Brionvega RR126 radiograph, which can be used to listen to five songs dear to Castiglioni (Maramao perché sei morto, Nel blu dipinto di blu, Yellow submarine, Somewhere over the rainbow, Sing sing sing) (Fig. 10) and the movable tv, which allows you to watch the documentary "Achille Castiglioni: tutto con un niente".
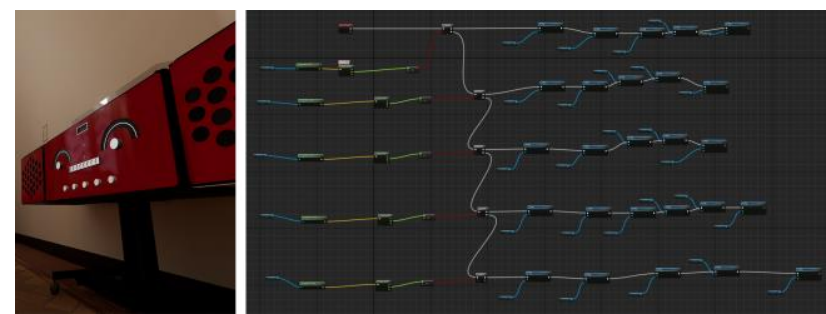

Figure 10. Blueprint of the Brionvega RR126 radiograph.

The experience was enriched by some details that allow to get directly in touch with Castiglioni's personality: this is the case of the designer's glasses, placed on the Leonardo table in the Mirror Room, the box with the phrase "Prototipi Gibigiana", (which can be opened to extract the Gibigiana table lamp and a photo that shows the various stages of the prototype development), or the original recording of Castiglioni's whistle, which the user can listen to during the visit and which allows to perceive the designer's presence, as if his spirit continued to live in the virtual museum.

To give the simulation its serious game character, a level challenge was developed, specifically designed to allow the visitor to familiarize with Castiglioni's personality and creative genius and to enter the Prototype Room, which is inaccessible at the beginning of the simulation. The aim is to underline the importance of this room: in fact, this is the place where Castiglioni used to create his works. Specifically, in order to complete the visit, the user is called to explore the museum and all the artefacts, so as to find some particular objects (the Arco lamp, the Taccia lamp, the designer's glasses, the Mezzadro chair, the poster of the MoMa exhibition in New York, the mobile TV), closely linked to Castiglioni's life and personality, interacting with which it will be possible to obtain extra information in the form of audio content. Only after having unlocked these extra contents, the visitor will be able to enter the Prototype Room, where he or she can face the last challenge, which consists in finding the box with the words "Prototipi Gibigiana", extracting the variants of the prototype (from the first to the final version) and placing them on the bookcase in the correct chronological order. To do this, the user will be helped by some holograms representing the shapes of the prototypes in their exact sequence. Once this challenge is overcome, it will be possible to listen to an audio in which the creative process followed by the designer in his activity is told. As a whole, this game is designed to allow the user to gradually come into contact with Castiglioni, first through objects that have a special connection with his professional activity and personality, then with the last challenge, which helps the visitor to understand all the design process behind an object, ideally completing the path to discover Castiglioni's genius.

\subsection{Testing stage}

The VR experience of the Studio Museo is currently undergoing a series of evaluation tests, aimed at judging the effectiveness of the design choices described in the previous paragraphs on the basis of feedbacks provided by users. This evaluation phase, currently underway, began during the Brainstorming BIM Conference, held in Milan on 18 October 2019. On this occasion, the virtual simulation was submitted to a sample of individuals, representative of the target categories of users who generally visit places such as the Studio Museo or have a particular interest in these sites (engineers, architects, university students, experts and design enthusiasts, etc.).

The test allowed to obtain first significant results, which overall showed a positive feedback.

In the same context, useful suggestions were collected to implement the simulation: in particular, many users, as experts in the field, expressed the desire to obtain, during the VR experience, more detailed information with a more specialized approach, preferably in the form of audio-visual contents that reproduce extracts from interviews by Castiglioni. Moreover, the sample expressed particular appreciation for the effectiveness of the level challenge, proposing to implement it through further forms of interaction, consisting for example in the possibility of assembling a design object starting from its components, in a sort of $3 \mathrm{D}$ puzzle game.

\section{CONCLUSION AND FUTURE WORK}

This project tried to demonstrate the infinite communication and educational possibilities offered by ICT in the promotion and enhancement of museum heritage. To this end, after analysing the evolutionary path that museums have gone through in the last decades, and after having identified the serious game as a possible innovation tool for museums, researchers have tried to outline a valid workflow (which includes both a technical-engineering and a psychological component) for the realization of a serious game that allows to experience a small museum institution: The Studio Museo Achille Castiglioni in Milan.

Virtual Reality was chosen as the most effective tool to develop the serious game, thanks to its ability to fully immerse the user in the game space and involve him or her physically and emotionally through interactive elements, allowing to learn by 
acting, to live a first-person experience as the protagonist of the visit and not just as a spectator.

The experimentation is still in progress: the research group is currently preparing new evaluation tests, in order to obtain feedback from users to understand what the most suitable strategies are to implement and improve the virtual experience and make it more effective, engaging and richer in content. The prototype, therefore, does not claim to have reached its final form. In particular, considering the small number of researchers (an engineer, an architect and the client) involved in this phase of the experimentation, a valid stimulus for further improvements can come from the expansion of the research group to professional figures from other fields of knowledge, such as psychologists, computer scientists, education experts, game developers, who can certainly contribute to integrate the workflow and the virtual simulation, making the outcome more multi-faceted and more complete.

\section{ACKNOWLEDGEMENTS}

The researchers would like to thank the members of the Achille Castiglioni Foundation (specifically Giovanna Castiglioni, Carlo Castiglioni, Antonella Gornati and Noemi Ceriani) for allowing the free access to all the rooms of the museum, for providing us with documents and images that are part of their collection and for helping and supporting us in the organization of the virtual museum exhibition. We also would like to thank RAD - Rete d'impresa per l'Artigianato Digitale (specifically Marco Cavalotto and Davide Manfredi) for truly believing in this project, supporting it professionally and economically.

\section{REFERENCES}

Abt, C.C., 1970. Serious Games. The Viking Press, New York, NY, USA.

Aiello, D., Santagati, C., Fai, S., 2019. Virtual Museums as a means of promotion and enhancement of Cultural Heritage. Int. Arch. Photogramm. Remote Sens. Spatial Inf. Sci., Vol. XLII2/W15, pp. 33-40.

Anderson, M., 1999. Museums of the Future: the impact of technology on museums practices. America's Museums. Vol. 128(3), pp. 129-162.

Arnab, S., Lim, T., Carvalho, M. B., Bellotti, F., de Freitas, S., Louchart, S., Suttie, N., Berta, R., and De Gloria, A., 2014. Mapping learning and game mechanics for serious games analysis. British Journal of Educational Technology, Vol. 46, pp. 391-411.

Barajas Saavedra, A., Rodriguez, F., Muñoz-Arteaga, J., Salgado, R., \& Collazos, C., 2014. A serious game development process using competency approach. Interacción '14: Proceedings of the XV International Conference on Human Computer Interaction, pp. 1-9.

Bellotti, F., Berta, R., De Gloria, A., D’Ursi, A., Fiore, V., 2012. A serious game model for cultural heritage. ACM Journal of Computing and Cultural Heritage, Vol. 5(4).

Camarero, C., and Garrido, E., 2011. Fostering Innovation in Cultural Contexts: market orientation, service orientation, and innovations in museums. Journal of Service Research. Vol. 15(1), pp. 39-58.
Cao, Y., Klamma, R., Jarke, M., 2011. The Hero's Journeytemplate-based storytelling for ubiquitous multimedia management. Journal of Multimedia, vol. 6(2), pp. 156-169 (Special Issue. Academy Publisher).

Carvalho, M. B., Bellotti, F., Berta, R., De Gloria, A., Sedano, C. I., Hauge, J. B., Hu, J., and Rauterberg, M., 2015. An activity theory-based model for serious games analysis and conceptual design. Comput. Educ., vol. 87, pp. 166-181.

Christopoulos, D., Mavridis, P., Andreadis, A., Karigiannis, J. N., 2011. Using virtual environments to tell the story: The battle of Thermopylae. Third International Conference on Games and Virtual Worlds for Serious Applications, Athens, 2011, pp. 8491.

Christopoulos, D., Gaitatzes, A., 2009. Multimodal Interfaces For educational virtual environments, informatics. 13th Panhellenic Conference on Informatics, pp. 197-201.

Doulamis, A., Liarokapis, F., Petridis, P., Miaoulis, G., 2011. Serious Games For cultural applications. In D. Plemenos, G. Miaoulis (Eds.), Artificial Intelligence Techniques for Computer Graphics, Springer.

Durkin, K., 2006. Game Playing and Adolescents' Development. In P. Vorderer \& J. Bryant (Eds.), Playing video games: Motives, responses, and consequences, Lawrence Erlbaum Associates Publishers.

Froschauer, J., Seidel, I., Gartner, M., Berger, H., Merkl, D., 2010. Design and evaluation of a serious game for immersive cultural training. Proc. 16th International Conference on Virtual Systems and Multimedia (VSMM), pp. 253-260.

Froschauer, J., Arends, M., Goldfarb, D., Merkl, D., 2011. Towards an Online Multiplayer Serious Game Providing a Joyful Experience in Learning Art History. Proceedings of the Third International Conference on Games and Virtual Worlds for Serious Applications (VS-GAMES).

Froschauer, J., Merkl, D., Arends, M., Goldfarb, D., 2013. Art history concepts at play with ThIATRO, ACMJ. Comput. Cult. Herit., vol. 6(2) (special issue on serious games for cultural heritage).

Guazzaroni, G., 2019. Role of Emotions in Interactive Museums: How Art and Virtual Reality Affect Emotions. In Giuliana Guazzoroni, Anitha S Pillai (eds.), Virtual and Augmented Reality in Education, Art, and Museums. Hershey, Pennsylvania (USA): IGI GLOBAL.

Gunter, G., Kenny, R. F., and Vick, E. H., 2006. A Case for a Formal Design Paradigm for Serious Games. J. Int. Digit. Media Arts Assoc., vol. 3, no. 2004, pp. 1-19.

Gunter, G., Kenny, R. F., and Vick, E. H., 2008. Taking educational games seriously: Using the RETAIN model to design endogenous fantasy into standalone educational games. Educ. Technol. Res. Dev., vol. 56, pp. 511-537

Haring, P., Chakinska, D. and Ritterfeld, U., 2011. Understanding Serious Gaming: A Psychological Perspective. In Patrick Felicia (ed.), Improving learning and motivation through educational games. Hershey, Pennsylvania (USA): IGI GLOBAL. 
Hempell, T., Van Leeuwen, G., and Van Der Wiel, H., 2004. ICT, Innovation and Business Performances in Services: evidence for Germany and the Netherlands. ZEW - Centre for European Economic Research Discussion, Paper No. 04-006.

Huang, C., Huang, Y., 2013. Annales school-based serious game creation framework for Taiwan indigenous cultural heritage. ACMJ Comput.Cult.Herit., vol. 6(2) (special issue on serious games for cultural heritage).

Jegers, K. and Wiberg, C., 2005. Learning While Playing: Design Implications for Edutainment Games. In Richard E. Ferdig (ed.), Effective electronic gaming in education. Hershey, Pennsylvania (USA): IGI GLOBAL.

Kang, Y., and Yang, K., 2019. Employing Digital Reality Technologies in Art Exhibitions and Museums: A Global Survey of Best Practices and Implications. In: Giuliana Guazzoroni, Anitha S Pillai (eds.), Virtual and Augmented Reality in Education, Art, and Museums. Hershey, Pennsylvania (USA): IGI GLOBAL.

Kargas, A., Karitsioti, N., and Loumos, G., 2019. Reinventing Museums in 21st Century: Implementing Augmented Reality and Virtual Reality Technologies Alongside Social Media's Logics. In: Giuliana Guazzoroni, Anitha S Pillai (eds.), Virtual and Augmented Reality in Education, Art, and Museums. Hershey, Pennsylvania (USA): IGI GLOBAL.

Laamarti, F., Eid, M. \& El Saddik, A., 2014. An Overview of Serious Games. International Journal of Computer Games Technology, vol. 2014, article ID: 358152.

Lee, K. M., \& Peng, W., 2006. A brief biography of computer game studies. In P. Vorderer \& j. Bryant (Eds.), Playing computer games: Motives, responses, and consequences. Mahwah, NJ: Erlbaum.

Lieberman, D., 2006. What Can We Learn from Playing Interactive Games? In P. Vorderer \& J. Bryant (eds.), Playing Video Games: Motives, Responses, and Consequences. Lawrence Erlbaum Associates.

Malone, T. W., 1980. What Makes Things Fun to Learn? A Study of Intrinsically Motivating Computer Games. Palo Alto: Xerox, Palo Alto Research Center.

Malone, T. W., 1981. Toward a Theory of Intrinsically Motivating Instruction. Cogn. Sci. A Multidiscip. J., vol. 5, pp. 333-369.

Novak, J., Fleischmann, M., Strauss, W., Valle, C., Peranovic, P., and Seibert, C., 2001. From Memoria Futura to i2TV: A technological framework and two models for new forms of cultural participation and production in mixed realities. Proceedings from International Cultural Heritage Informatics Meeting.

Ritterfeld, U, \& Weber, R., 2006. Video games for entertainment and education. In P. Vorderer \& J. Bryant (Eds.), Playing video games-Motives, responses, and consequences. Mahwah, NJ: Erlbaum.
Rodriguez, F., Barajas Saavedra, A., \& Muñoz-Arteaga, J., 2014. Serious Game Design Process, Study Case: Sixth Grade Math. Creative Education, vol. 5, pp. 647-656.

Srinivasan, R., Boast, R., Furner, J., and Becvar, K. M., 2009. Perspective: Digital Museums and Diverse Cultural Knowledges: moving past the traditional catalogue. The Information Society, vol. 25, pp. 265-278.

Tanguy, C., 2013. MuseUs: case study of a pervasive cultural heritage series game. ACMJ Comput. Cult. Herit., vol. 6(2) (special issue on serious games for cultural heritage).

Watt, J. H., 2009. Improving methodology in serious games research with elaborated theory. In U. Ritterfeld, M. J. Cody, \& P. Vorderer (Eds.), Serious games: Mechanisms and effects. New York: Routledge/LEA

Witcomb, A., 2003. Re-Imagining the Museum: beyond the mausoleum. London: Routledge.

Zyda, M., 2005. From visual simulation to virtual reality to games. Computer, vol. 38(9), pp. 25-32.

http://fondazioneachillecastiglioni.it/la-fondazione/

http://archives.icom.museum/definition.html 